\title{
Is Systemic Change Part of Pro-poor Business Approaches?
}

\author{
Jodie Thorpe
}

\begin{abstract}
Business is increasingly seen as central to international development, given the power of companies within markets and other related systems that affect the lives of the poor. However, there is a rising sense that these approaches have generally not achieved substantial impact over the long term or at large scales. Based on a multi-level perspective of systemic change, this article explores evidence from nine case studies of pro-poor business initiatives, to examine their potential to go beyond individual company value chains and drive positive shifts in broader market systems. The analysis suggests that initiatives based around existing company value chains are less likely to be systemic than those involving the creation of new companies or platforms of actors from different parts of society. The article concludes with some implications for development agents working with business.
\end{abstract}

\section{Introduction}

Business is increasingly seen as central to international development, given the power of companies within markets and other systems that affect the lives of the poor. 'Pro-poor business', which aims to redesign business models and processes to improve the lives of the poor as producers linked to value chains, as consumers of essential goods and services, or as employees, is one such approach. Often led by companies, sometimes in partnership with development agents including non-governmental organisations (NGOs) and donors, pro-poor business initiatives are gaining in popularity (Humphrey et al. 2014). Donors, for example, have provided 'challenge' grants to lead firms as one-off investments, facilitated business linkages and invested in direct value chain development (Miehlbradt and McVay 2006). For the International Finance Corporation (IFG), such business models have accounted for over US $\$ 7$ bn in commitments, working with more than 300 clients in over 80 countries in recent years (Ishikawa and Ribeiro 2012).

However, there is a rising sense that these approaches have generally not achieved substantial impact over the long term (WBCSD 2013; Jenkins and Ishikawa 2010; Newnham 2010). Research by the Harvard Kennedy School Corporate Social Responsibility Initiative finds that inclusive business projects have failed to reach their full potential because they have generally been carried out in isolation from broader efforts by other stakeholders to tackle deep problems or 'systemic barriers'.

It has become clear that for companies to maximise their contributions to development, they need to engage in a combination of both business model innovation with the potential for long-term sustainability and broad, multistakeholder collaboration to remove systemic barriers to scale and impact (Gradl and Jenkins 2011:4).

This article explores a series of practical examples of pro-poor business initiatives, drawing on the work of the United Nations Development Programme's (UNDP) Growing Inclusive Markets (GIM) initiative, ${ }^{1}$ to examine their potential to go beyond individual company value chains, to drive positive shifts in broader market systems.

\section{Systemic change}

Williams (2015) describes a system as being characterised by interrelationships, perspectives and boundaries. Systems are dynamic patterns of interrelationships involving actors, objects and processes, which operate within a set of boundaries (defining what falls within or outside that 
system). These boundaries and other properties of the system are subjective - their definition is often based on the perceptions of interested parties, and may be experienced and understood differently by different individuals, based upon their position, role and experiences of the system (Checkland 1981). In order to analyse systems, it is therefore important to consider multiple perspectives. In 'complex' systems like markets, which consist of many individual but interdependent parts, the patterns and dynamics of the system emerge from interactions between these parts. Individuals are both affected by and adapt to other actors' decisions.

'Systemic change' implies a transformation in the structure or dynamics of a system, which leads to impacts on the material conditions or behaviour of large numbers of people (Osorio-Cortes and Jenal 2013). Systemic approaches aim to catalyse change, inducing spill-over effects (Ruffer and Wach 2013) with broad direct and indirect impacts. For example, if a company provides financing directly to an agricultural cooperative it works with, to allow that cooperative to invest in crop improvements, this impact is limited to a relatively small group of people. Based on the concepts identified above, it would not be considered systemic. However, if that company instead works with local government, businesses, cooperatives and others to create a rural credit mechanism that is open to farmers both within and outside the value chain, this can lead to systemic change that impacts a broad group of people, and (if successful) can outlast the involvement of the company.

In the context of pro-poor business initiatives, systemic change is often seen as desirable, a way of driving positive development outcomes at scale. However, there is nothing inherent in systemic change that leads to this conclusion. There are likely to be winners and losers from systemic change, and the benefit of any particular change is likely to depend on the perspectives of different individuals.

Moreover, systemic change in markets is difficult to design and manage, since initiatives to create change are likely to have unpredictable outcomes, depending on the ways in which the individual parts of the system respond. Interventions are affected by positive and negative feedback loops, for example, that escalate or stifle change.
Negative feedback loops in particular can be difficult to detect, since they are balancing loops that mean that large efforts may result in little systemic effect. On the other hand, when discontinuities arise - major disruptions that provide opportunities for change - efforts that would otherwise be resisted can sometimes break through.

\subsection{Multi-level perspective}

Geels and Schot's (2007) 'multi-level perspective' builds on this idea of external pressures which create windows of opportunity for systemic change. Changes in systems, which they term 'socio-technical regimes', are influenced by both micro-level 'niche innovations' and by discontinuities caused by changes in the macrolevel 'socio-technical landscape' in which the system operates. Since systemic change is difficult to design, the focus of action is on the 'niche innovations' - programmes and activities that promote unique behaviours and which deviate in one or more dimensions from existing systems, often pioneered by entrepreneurs or other relative outsiders. ${ }^{2}$ Niche innovations create pre-conditions for systemic change but are generally insufficient to catalyse change on their own, requiring discontinuities that can destabilise the system and overcome negative feedback loops and path dependence (Unruh 2000). Destabilising events come through changes in the macro landscape that create pressure on the existing system and windows of opportunity for niche innovations to take hold.

For example, Geels and Schot identify the British transition from sailing ships to steamships as one case of systemic change. Sailing ships were the dominant form of transport in the midnineteenth century. Steamships also existed and were faster, but were also more expensive and confined to a small niche, particularly for mail steamers to improve communication within the British Empire. However, a number of changes that followed, notably mass emigration from Europe that boosted transatlantic trade, development of the coal industry, and the opening of the Suez Canal (which could not be used by sailing ships) created discontinuities. Although the initial reaction was to introduce more masts and sails to increase the speed of sailing ships, and to make them larger to increase cargo capacity, steam had largely displaced sails before the end of the century. 
Most niche innovations are embryonic - with small and unstable communities of actors, poorly developed structures, and rules that are poorly articulated and understood (Geels and Schot 2007). Most niche innovations will never challenge the existing system. Systemic change is most likely to arise when external pressures exist at the same time as consolidation of niche innovations have taken place, such that they are sufficiently developed to take advantage of the window of opportunity that has arisen. If pressures arise at a moment when niche innovations are not well developed, then the system may adapt, rather than change. If pressures are absent then the existing system will tend to reproduce itself, often accompanied by incremental changes that improve system performance over time.

\subsection{Recognising consolidation of niche innovations}

Recognising systemic change in progress is not straightforward, since it involves changes not only in tangible outputs and products, but also and often more importantly in processes, relationships and attitudes or social norms, all of which may be difficult to observe in practice. However, Geels and Schot (2007) propose the following proxies as reasonable indicators for the stabilisation of viable niche innovations that are ready to break through more widely:

- The stabilisation of learning processes in a dominant design;

- The appearance of powerful actors as part of the support network;

- Price/performance improvements, with strong expectations of further improvement;

- The use of the innovation in market niches that together amount to more than 5 per cent of market share.

\section{Systemic change and pro-poor business}

Most pro-poor business innovations are based on a linear 'cause and effect' theory of change, with outcomes seen as predictable in advance and strategies based around designing solutions to problems (Mowles, Stacey and Griffin 2008), without taking into account the nature of markets as complex adaptive systems.

However, putting pro-poor business in the language of the multi-level perspective, new business models that are more inclusive of the poor as producers, consumers and employees may plant the seeds of systemic change if they involve niche innovations. These innovations are likely to be developed by small networks of dedicated and often fringe actors and starting with unstable, low-performance configurations incubated within niches that protect them against mainstream market selection. They struggle against the existing system and disappear unless they become more established through the stabilisation of rules, institutions, relationships and norms, and through gaining the support of powerful actors. When changes in the external environment, such as political change, new technologies or changes in social dynamics destabilise the current system, a window of opportunity may be created for these innovations to break through and change the way the system operates more broadly.

According to Gradl and Jenkins (2011), the process of stabilising pro-poor business innovations involves creating communities or networks of interconnected, interdependent players, including companies, governments, business associations, NGOs, public and private donors, research institutes and the media. Aligning the objectives of different players and strengthening these 'ecosystems' are likely to be slow and complex processes, but strategies to speed them up include awareness-raising and capacity building up and down the value chain; information-sharing around new organisations, rules and markets; public policy dialogue; and creating new organisations such as intermediaries, research and training institutes, certification bodies, and market services providers.

Gradl and Jenkins also identify three basic structures that companies employ in inclusive business initiatives. The default structure is a 'private initiative' in which the company has sufficient resources and capabilities to develop the innovations and does not face significant incentive problems, such as the risk of freeriders. When challenges exist with resources, capabilities and incentives, companies may form 'project-based alliances' with two or more actors in a formal agreement to accomplish a certain objective within a set time frame, or 'platforms' involving a network of a potentially large number of stakeholders, which is dependent on the membership for strategic direction-setting, programming and governance. 


\section{Review of pro-poor business case studies}

There is currently a lack of good evidence, information and case studies on pro-poor business and systemic change. Even where business initiatives have aimed to achieve systemic change, analyses and impact assessments have been weak at reviewing systemic aspects (Ruffer and Wach 2013). The rest of this article seeks to review a sample of pro-poor business case studies to draw some conclusions about whether and how business-led approaches can go beyond an individual value chain to create the potential for broader systemic change.

The cases were selected from the UNDP's GIM initiative, ${ }^{3}$ focusing on the subset of agricultural sector cases from the first set of GIM studies. ${ }^{4}$ The focus on a single sector is intended to make comparisons easier by limiting the number of potential variables in the analysis, and agriculture is selected given its strong links to poverty and development (Wiggins, Kirsten and Llambi 2010; Chang 2009; Ravallion and Datt 1996).

The case studies are:

1 Amanco, Mexico: Development of a hybrid value chain model for serving low-income markets, in partnership with civil society organisations (Serrano 2007).

2 Coco Technologies (CocoTech), Philippines: Establishment of bioengineering applications of cocofibre nets made from waste coconut husks (Ganchero and Manapol 2007).

3 Fair Trade Cotton, Mali: Fair trade cotton initiatives to help poor Malian farmers (Gaye 2007).

4 Integrated Tamale Fruit Company (ITFC), Ghana: Development of an outgrower scheme allowing farmers to enter mango production with long-term income prospects (Osei 2007).

\section{Juan Valdez Coffee Shops, Colombia:}

Increasing coffee producers' profits by incorporating direct sales into the commercial model of the National Federation of Coffee Growers of Colombia (NFC) (Serrano and Avella Villegas 2007).

6 Natura, Brazil: Establishing supplier relationships with rural communities to extract raw material from Brazilian vegetal biodiversity (Boechat and Mokrejs Paro 2007).

7 Sadia, Brazil: Reducing greenhouse gas emissions from swine producers in Sadia's supply chain and selling carbon credits under the Kyoto Protocol Glean Development Mechanism (CDM) (Boechat, Werneck and Miraglia 2007).

8 Sekem, Egypt: Promoting social and environmental development through economic and cultural activities, based around eight companies focused on agriculture (Hatem 2007).

\section{Sustainable Cashew Production, Guinea:}

Helping Guinean farmers by supporting the planting or rehabilitation of cashew plantations and training farmers' associations (Gaye and Moreau 2007).

These cases were analysed based on five questions, designed to probe the relationship between these business and development initiatives and systemic change. The questions are derived from the literature review (particularly Gradl and Jenkins 2011; Geels and Schot 2007; Freeman and Perez 1988; Checkland 1981).

1 What was the structure of the pro-poor business initiative? Four structures were considered: initiatives led by an existing company, initiatives led by a new company created in response to a specific development challenge, formal partnerships between two or more entities, ${ }^{5}$ and multi-party platforms involving a large number of organisations with broad, shared objectives.

2 Were elements of systemic change part of the design of the initiative? Did the initiative explicitly seek to address systemic challenges? Did the initiative involve deliberate innovation, especially multiple innovations in product, process and organisation?

\section{Which approaches were utilised to} strengthen and stabilise innovations? The cases identified as taking a systemic approach designed to address systemic challenges were reviewed for evidence of the strategies used to strengthen and stabilise innovations; for example, creating new organisations to fill 
gaps around key market functions or reflecting diverse perspectives of the system.

4 Is there evidence in the case studies of strengthening and stabilising innovations?

The cases that were identified as being designed to address systemic challenges were analysed for any evidence that strengthening and stabilisation of innovations was taking place.

5 Were there indirect links to systemic change? Since systemic change is difficult to manage and design, with often unpredictable outcomes, the initiatives were reviewed for evidence captured in the case studies that they may be contributing to systemic changes in ways that were not necessarily planned or intended.

This analysis is based on a desk review of existing case studies, which provide a ready source of data to test the frameworks derived from the literature review. However, the cases were not written from a perspective of systemic change, meaning that relevant questions may not have been asked and relevant evidence may have been left out of the case studies. In addition, the sample size of nine cases is small and focused only on agriculture. While agriculture as a sector is highly relevant to development, the results are not necessarily representative of other sectors.

Note finally that, as systemic change is not predictable, the intention here is not to make judgements about which of these initiatives will lead to systemic change. Many of these innovations will struggle against the existing system and disappear. Rather, the aim is to identify those cases that seem to be creating the building blocks for systemic change, through developing and consolidating niche innovations that can break through if the conditions are right. Follow-up research could review how these projects have evolved over time and whether and how they have affected systems.

\section{Results}

\section{What was the structure of the pro-poor} business initiative?

Three of the nine cases involved an existing company that added a pro-poor business approach to its operations: ITFC, Natura and Sadia, while three cases involved setting up a new company in order to develop a pro-poor business approach: CocoTech, Juan Valdez and Sekem. There was one project partnership - this was the Amanco case study, based on a partnership between Amanco, a civil society organisation, Ashoka, and a social entrepreneur. There were two examples of platforms, Fair Trade Cotton, with the support of NGOs, European clothing retailers and a number of government entities; and Sustainable Cashew Production led by the Global Development Alliance Partnership encompassing cashew cooperatives, the Guinean government, the United States Agency for International Development (USAID) and Kraft Foods.

\section{Were key elements of systemic change part of the design of the initiative?}

The question here is to understand whether the initiatives addressed systemic challenges and did this through deliberate innovation efforts, rather than focusing only on a company's value chain or on incremental improvements that strengthen or adapt the existing system. Only three of the nine cases were designed in this way. Two were new companies: CocoTech, which pioneered bioengineering applications of cocofibre nets from waste coconut husks, providing supplementary income to coconut farmers; and Sekem, which developed agriculture-based manufacturing in medicine, food and fabrics to promote social and environmental development. One was a platform, Fair Trade Cotton, which innovated with the aim of making an existing sector work in a more pro-poor way. The other six cases focused on single value chains or undertook only relatively incremental improvements to improve chain function, or both.

\section{Which approaches were utilised to strengthen and stabilise innovations?}

The three cases that aimed to achieve systemic change used a range of approaches. CocoTech undertook a consultation with leaders of the country's coconut industry and local public works officials to understand diverse perspectives on the challenges being faced. ${ }^{6}$ It also engaged in public policy dialogue towards a Presidential Memorandum mandating the use of cocofibre in government infrastructure projects. CocoTech also addressed power imbalances in the market by strengthening the autonomy of community partners and their bargaining power towards the Philippine government. 
Sekem helped form a new organisation, the Egyptian Biodynamic Association (EBDA), to conduct research and support initiatives to promote organic agriculture. The investment in EBDA has also strengthened the community of institutions promoting organic agriculture in Egypt. Sekem also took measures to share information related to biodynamic agriculture, working with the North Africa Enterprise Development Facility to enhance communication and collaboration with small- and medium-sized farmers, including through improved production forecasts.

The Fair Trade Cotton initiative undertook efforts to raise awareness on fair trade cottonbased products amongst European manufacturers and consumers. It also ensured that a 'development premium' was built into the fair trade model, providing funding to farmers' organisations or cooperatives to spend on collective projects that provide missing public goods in areas like health, education, environment and the economy. The initiative was also part of the broader Fairtrade movement that seeks to improve the position of small-scale farmers in world markets.

\section{Is there evidence of consolidation of niche innovations?}

In each of the cases, there were some indicators of the strengthening of innovations, although the information was limited. For CocoTech, what started in one part of the Philippines spread to other coconut-producing areas, indicating a potential stabilisation of learning processes towards a dominant design. New communities of supporters also became interested in the innovation, with partnerships and joint ventures established with foreign companies and governments in the Netherlands, China and Sri Lanka. There was also market growth, with new international customers such as Bestmann in Germany. However, overall, the number and value of CocoTech's projects peaked in 2002/03, fell in 2005 and only started climbing again in 2006. Systemic change can often develop in nonlinear or unpredictable ways, depending on the parts of the system and how they respond.

For Fair Trade Cotton, there was a wide community of supporters, including fair trade organisations, French, Belgian, Swiss and UK clothing retailers, the French textile development organisation Dagris, Malian cottongrowing companies and the French Ministry of Foreign Affairs. Demand for certified cotton showed a twelvefold increase in 2005/06. However, with the successful production of highquality fair trade cotton, one of the partners, Dagris, began marketing new brands based on quality and not on Fairtrade certification (although still sourcing from certified producers). This development could potentially be a sign of the stabilisation of fair trade in a dominant design. However, other project partners saw it as potentially reducing awareness of the fair trade approach, and therefore undermining its stabilisation.

Finally, for Sekem, the company has been successful in building the community of supporters through cooperation agreements with governments and alliances with NGOs in the field of biodynamic agriculture. The case study also reports a 'landmark achievement' of reducing the use of synthetic pesticides in Egypt by over 90 per cent, while also increasing the yield of raw cotton by almost 30 per cent, through the utilisation of an innovative technique to shield the cotton plant. This seems to indicate stabilisation around this particular innovation as a dominant design. There is no information, however, on market or demand growth across the different markets and products that Sekem is involved in.

\section{Did the initiatives contribute indirectly to other systemic changes?}

In several of the cases, including both initiatives that were targeting systemic change and those that were not, potential indirect systemic aspects were identified. For example, given the critical role that women play in the CocoTech supply chain, women are reported to have acquired a greater sense of importance and selfesteem, and this may affect women's overall standing in communities. The initiative has also supported increased cooperative membership, which may help strengthen the cooperative network in the Philippines, where these organisations frequently struggle. ${ }^{7}$ In the Sadia case, the initiative was helping to create a group of trained individuals who could fill gaps around CDM project implementation. Other examples include ITFC, which is helping to reinforce government policy on reforestation, and Amanco which, with funding from the Inter-American 


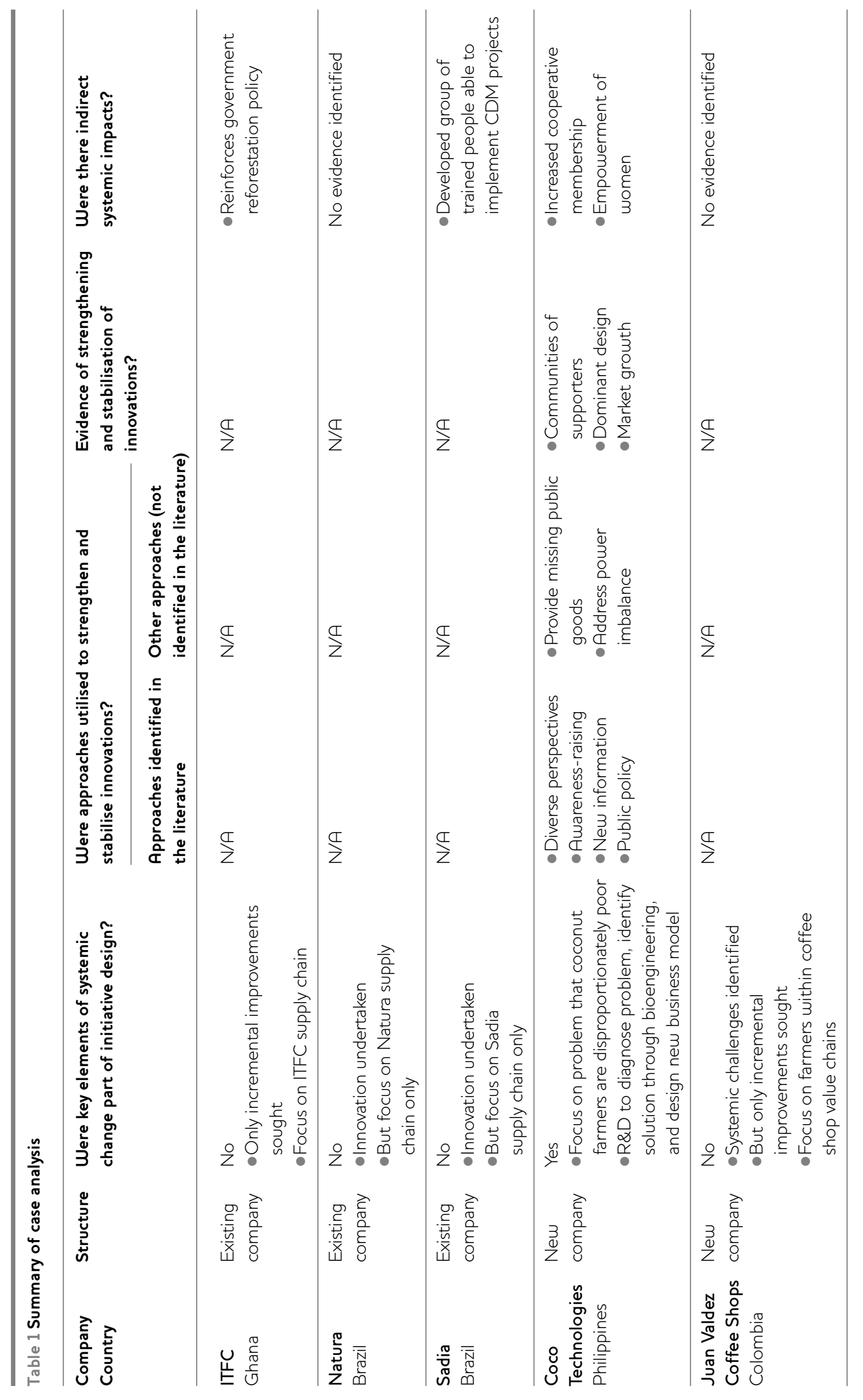

76 Thorpe Is Systemic Change Part of Pro-poor Business Approaches? 


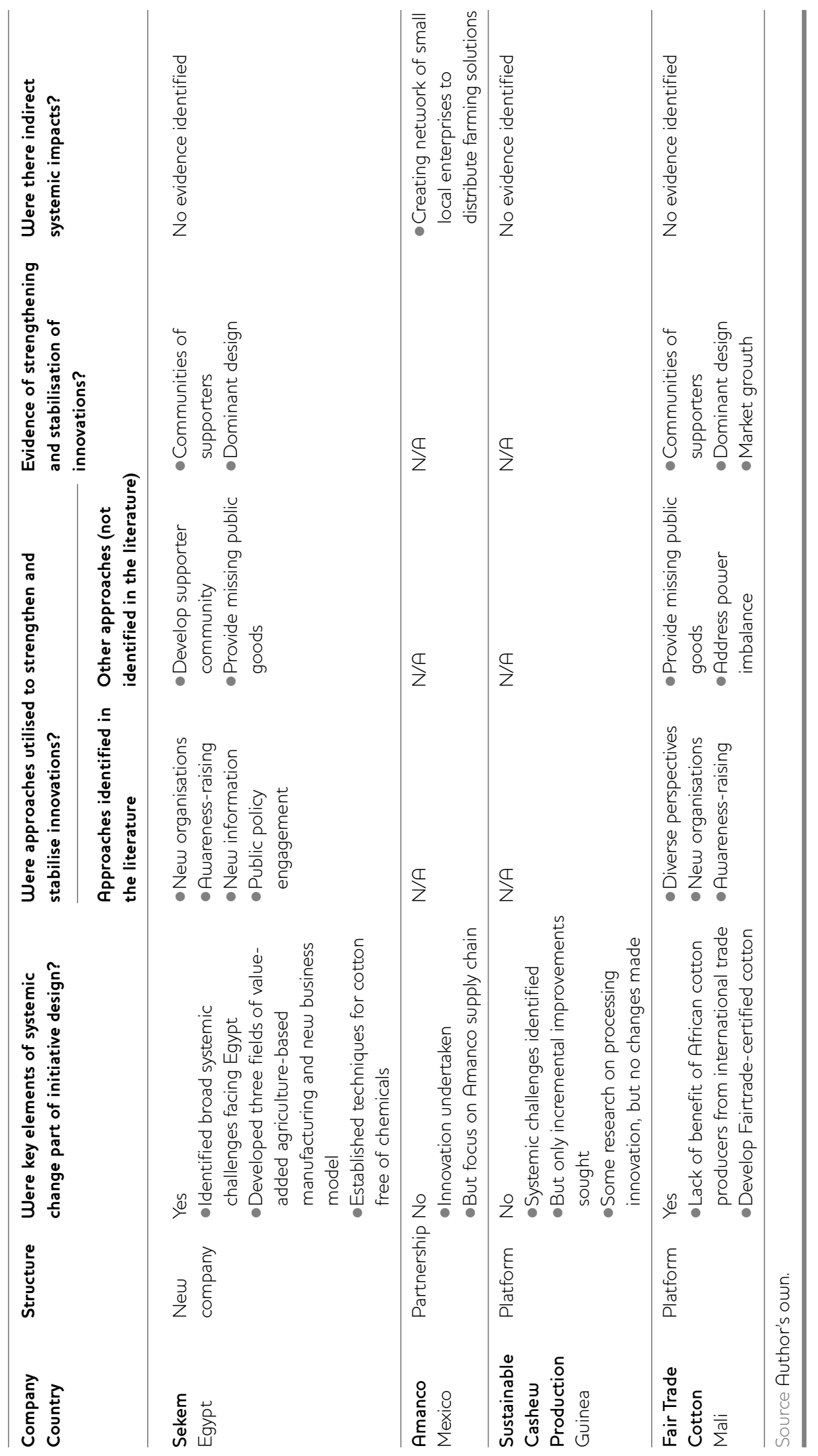


Development Bank, was creating a network of small local enterprises to act as distributors of irrigation, but also other agricultural solutions for small-scale producers, such as greenhouses.

\section{Conclusion - is systemic change part of the business and development approach?}

This analysis of nine pro-poor business case studies suggests that initiatives based around existing company value chains, including partnerships between a company and a development agent, tend not to take a systemic approach. This finding does not mean that these initiatives fail to tackle poverty, but that direct impacts are likely to be limited to producers, consumers or employees in the company's value chain, rather than reaching others outside of that value chain and being sustainable beyond the involvement of the company. Initiatives where new companies were created or where platforms of actors came together, on the other hand, were more likely to be systemic in approach.

This analysis is based on a desk review of pro-poor business case studies, which provided a ready source of information to test ideas and frameworks on systemic change. However, there are obvious limitations. The cases were not written from a perspective of systemic change and given the small sample size, further analysis involving primary research with a greater number and variety of cases, and testing these findings and exploring results over a longer time horizon (10-15 years) would provide a deeper understanding of pro-poor business models and systemic change.

There are, however, three key findings from the evidence so far. Firstly, amongst the cases that targeted systemic change, a wide range of approaches were adopted to strengthen and stabilise innovations. These include developing understanding of the system based on diverse perspectives, creating new organisations, raising awareness and capacity amongst those involved in or targeted by the innovation, creating and making available new information, public policy engagement and influence, developing a wide community of supporters, addressing missing public goods and addressing power relations. This is by no means a blueprint of unique approaches that can drive systemic change, ${ }^{8}$ but points to some of the many ways initiatives may strengthen niche innovations, creating the potential for systemic change.
Strikingly, evidence was weak for two approaches that may be particularly important in order for systemic change to address poverty and development: building an understanding of the system based on diverse perspectives and addressing power relations. A critical part of what defines a system is how its power relations and structures operate, and this in turn impacts poverty and equity outcomes. In markets, those with economic or political power shape the system and also often define what are perceived to be the barriers or failures in the system and what are viable options to address these. Others may be so powerless that they are excluded or only participate in the market on poor terms (Sahan and Fischer-Mackey 2011), with little or no voice. While most of the cases included some efforts to understand diverse perspectives of the system, these generally focused more on the perspectives of powerful actors such as those within governments, rather than more marginalised communities or members of communities. Power-related issues such as the negotiating power between companies and smallholders, or questions of who governs collective organisations such as cooperatives were generally not considered.

Finally, while only three of the initiatives appeared to target systemic change, most of the initiatives dealt with some issues that were systemic in nature - affecting not only one company and its value chain, but many other actors and organisations too. In some cases the response, particularly from big business, was to simply navigate around these constraints, helping those within their value chain to avoid the problem. However, in a few cases the company sought to address the underlying systemic challenge, in ways that had the potential to result in wider benefits. When Amanco identified that public resources that could help farmers purchase small-scale irrigation technologies were being captured by wealthier farmers, for example, it planned to work with Mexican authorities to facilitate a more pro-poor resource allocation for the acquisition of small-scale irrigation.

\subsection{Implications}

The findings raise some important issues, which development agents should consider when working with business. Firstly, working with a new company or a network of organisations could provide a more likely starting point for systemic 
change than working with a single company, especially one that is heavily embedded or dominant in the current system. However, when working with an existing company on pro-poor business, development agents can play a role in incentivising companies to address challenges systemically or strengthen linkages between aspects of a value chain approach and broader systemic change efforts. Conversely, development agents should avoid circumstances where benefits created through company initiatives are contingent on factors that can undermine positive systemic change. Initiatives should not be premised on further entrenching an existing company monopoly, for example.

\section{Notes}

1 The GIM approach, supported by an advisory board of 25 development and business institutions, was intended to build empirical evidence of strategies in inclusive market development. Cases are developed in an academic manner, derived from a mix of primary and secondary sources, and subjected to peer review before publication (http://cases.growinginclusivemarkets.org/).

2 Dominant system actors may also engage in niche innovation as hedging or diversification strategies that are intended to maintain the status quo.

3 Growing Inclusive Markets (GIM) is a repository of 150 pro-poor business models from over 40 countries, authored by 45 Southern academics and practitioners. The GIM initiative, supported by an advisory board of 25 development and business institutions, was intended to build empirical evidence of strategies in inclusive market development. Cases are developed in an academic manner, derived from a mix of primary and secondary sources, and subjected to peer review before publication (http://cases.growinginclusivemarkets.org/).

\section{References}

Boechat, C. and Mokrejs Paro, R. (2007) Natura's Ekos: Perfume Essences Produce Sustainable

Development in Brazil, GIM Case Study A032, New York NY: United Nations Development Programme

Boechat, C.; Werneck, N. and Miraglia, L. (2007) Sadia Program for Sustainable Swine Production (3S Program): Bringing Sustainability to the Supply
Development agents should invest in ensuring that diverse perspectives, including those of marginalised people, are reflected in building an understanding of the system, its characteristics and challenges. They should also be aware of, identify and address power relations that perpetuate poverty and inequality. Finally, they can play a key role in evaluating systemic outcomes and impacts. These are areas where the public interest is likely to outweigh private benefits, and where there may be outright disadvantages for companies. It is particularly important, therefore, that these aspects are supported by non-commercial actors.

4 Two Growing Inclusive Markets surveys were conducted, with final results released in 2008 for the first survey and in 2010 for the second survey.

5 Note that while all the initiatives involve some level of commercial partnerships and collaborations at certain points along the life of the project, the key question here is whether the initiative was led by a partnership of organisations.

6 While most of the cases mentioned some effort to engage some stakeholders in developing the initiative, this reflected a comprehensive effort to reflect diverse perspectives. This may partly be a weakness in the case write-ups, lacking information on this point. However, it may also indicate that despite a strong emphasis on communication and awareness-raising, there was insufficient effort invested in understanding diverse perspectives.

7 The case study notes that in the Philippines, less than 10 per cent of cooperatives survive.

8 Note too that many of these strategies were also found in initiatives that were not identified as focusing on systemic change.

Chain, GIM Case Study A038, New York NY: United Nations Development Programme Chang, H.-J. (2009) 'Rethinking Public Policy in Agriculture: Lessons from History, Distant and Recent', Journal of Peasant Studies 36.3: 477-515 Checkland, P. (1981) Systems Thinking: Systems Practice, Chichester: Wiley

Freeman, C. and Perez, C. (1988) 'Structural

Crises of Adjustment, Business Cycles and 
Investment Behaviour', in G. Dosi,

C. Freeman, R. Nelson and L. Soete (eds), Technical Change and Economic Theory, London and New York NY: Pinter Publishers

Ganchero, E.G. and Manapol, P. (2007) Coco Technologies: Providing Livelihood Opportunities for Poor Coconut Farmers through Value-Adding, GIM Case Study A012, New York NY: United Nations Development Programme

Gaye, M. (2007) Fair Trade Cotton in Mali, GIM Case Study A006, New York NY: United Nations Development Programme

Gaye, M. and Moreau, O. (2007) Sustainable Cashew Production in Guinea, GIM Case Study A024, New York NY: United Nations Development Programme

Geels, F.W. and Schot, J. (2007) 'Typology of Sociotechnical Transition Pathways', Research Policy 36.3: 399-417

Gradl, C. and Jenkins, B. (2011) Tackling Barriers to Scale: From Inclusive Business Models to Inclusive Business Ecosystems, Cambridge MA: CSR Initiative, Harvard Kennedy School

Hatem, T. (2007) SEKEM: A Holistic Egyptian Initiative, GIM Case Study A041, New York NY: United Nations Development Programme Humphrey, J.; Spratt, S.; Thorpe, J. and Henson, S. (2014) Understanding and Enhancing the Role of Business in International Development: A Conceptual Framework and Agenda for Research, IDS Working Paper 440, Brighton: IDS

Ishikawa, E. and Ribeiro, C. (2012) Being the Change: Inspiring the Next Generation of Inclusive Business Entrepreneurs Impacting the Base of the Pyramid, Washington DC: International Finance Corporation

Jenkins, B. and Ishikawa, E. (2010) Scaling Up Inclusive Business: Advancing the Knowledge and Action Agenda, Washington DC: International Finance Corporation and CSR Initiative, Harvard Kennedy School

Miehlbradt, A.O. and McVay, M. (2006) Implementing Sustainable Private Sector Development: Striving for Tangible Results for the Poor, The 2006 Reader, Turin: International Labour Organization

Mowles, C.; Stacey, R. and Griffin, D. (2008) 'What Contribution can Insights from the Complexity Sciences Make to the Theory and
Practice of Development Management?', Journal of International Development 20: 804-20

Newnham, J. (2010) 'Scaling Inclusive Business: Why do Some Successful Inclusive Business Pilots Fail to Scale?', Inside Inclusive Business 10, http://businessinnovationfacility.org/page/ publications-inside-inclusive-business (accessed 26 June 2014)

Osei, R.D. (2007) Integrated Tamale Fruit Company: Organic Mangoes Improving Livelihoods for the Poor, GIM Case Study A021, New York NY: United Nations Development Programme

Osorio-Cortes, L. and Jenal, M. (2013) Monitoring and Measuring Change in Market Systems Rethinking the Current Paradigm, Arlington VA: SEEP Network

Ravallion, M. and Datt, G. (1996) 'How Important to India's Poor is the Sectoral Composition of Economic Growth?', World Bank Economic Review 10.1: 1-25

Ruffer, T. and Wach, E. (2013) Review of M4P Evaluation Methods and Approaches, ITAD Report, Hove: ITAD

Sahan, E. and Fischer-Mackey, J. (2011) Making Markets Empower the Poor: Programme Perspectives on Using Markets to Empower Women and Men Living in Poverty, Oxfam Discussion Paper, Oxford: Oxfam

Serrano, L. (2007) Amanco: Providing Irrigation Systems to the Rural Poor, GIM Case Study A003, New York NY: United Nations Development Programme

Serrano, L. and Avella Villegas, L.F. (2007) Juan Valdez Coffee Shops: Fair Trade as an Inclusive and Sustainable Business, GIM Case Study A022, New York NY: United Nations Development Programme

Unruh, G.C. (2000) 'Understanding Carbon Lock-in', Energy Policy 28.12: 817-30

WBCSD (2013) Scaling Up Inclusive Business: Solutions to Overcome Internal Barriers, WBCSD Brief, Conches-Geneva: World Business Council for Sustainable Development

Wiggins, S.; Kirsten, J. and Llambi, L. (2010) 'The Future of Small Farms', World Development 38.10: 1341-8

Williams, B. (2015) 'Prosaic or Profound? The Adoption of Systems Ideas by Impact Evaluation', IDS Bulletin 46: 7-16 